\section{Pesquisa bibliográfica}

Resp.: Heraldo Vasconcellos

Chefe do Serviço de Documentação da Biblioteca Karl A. Boedecker, da $E A E S P / F G V$

\section{Participação comunitária}

Esdras Borges Costa

Professor no Departamento de Fundamentos Sociais e Juridicos da Administração, da EAESP/FGV.
Esta bibliografia é um registro evidentemente parcial de trabalhos referentes a um assunto sem dúvida importante, mas de contornos conceituais que carecem de melhor definição.

$A$ idéia de "participaçāo comunitária' aparece, nas últimas décadas, em contextos tão diferentes como, por exemplo, a história das comunidades eclesiais de base (63), experiências pioneiras de administração municipal participativa (21 e 64), ou a atuação de órgãos governamentais no sentido de estimular e normatizar 0 envolvimento da população em programas especificos de administração pública. $(6,12,14,18$ e 20)

Âs avaliaçōes práticas e teóricas de tais experiências, somam-se estudos criticos nos quais o empenho de organizar conceitos sistematicamente, e explicitar claramente os enfoques $e$ pressupostos, corre paralelo com o registro detalhado e rigoroso de diversos casos de "participação comunitária".(37)

Um desses estudos criticos (69) aponta a distinção básica entre a participação que "é quase por definição um atributo da sociedade organizada', e a participação que "é realmente testada" nos "momentos de contestaçẫo" em que "se estabelece um conflito entre os setores decisionais da sociedade e esta". É neste segundo sentido que $o$ assunto se torna momentoso. Isto é, a questão da participação vem à tona como problema quando "as decisōes do aparelho de estado provocam nas populaçôes (...) conflitos sociais sobre a gestão dos recursos" - ou conflitos entre governantes e governados, ou conflitos entre subgrupos de interesses opostos entre os próprios governados.

Nessas condiçôes, qual seria o papel da participaçāo comunitária? Absorver as pressóes $e$ os conflitos $e$ assim "conferir legitimidade à açẫo do Estado"? "Ajudar os planejadores a programar suas açōes de maneira menos conflituosa"? Prejudicar o planejamento por ameaçar a rapidez das decisōes? "Paralisar as af̧öes audaciosas necessárias à solução dos grandes problemas"? Contribuir para a "educação da massa",

"conscientização de classe" e o

"treinamento de comportamento politico"?

Quando limitado ao nivel por demais genérico da participação que "é quase por definiçāo um atributo da sociedade organizada", o debate perde relevância, pois passa ao largo da questäo do poder; particularmente o poder de se decidir manter ou mudar determinada situação de dominaçāo. $(69$, p. 15)

Em uma das versōes desta questão, a noção de classe social é central, e duas hipóteses afloram: ou a "participação em si", embora sem levar a alteraçōes na "estrutura da dominaçāo de classe", resultaria em uma "conquista de consciência", pela qual a população

"progressivamente" tomaria $e$ conduziria os instrumentos do Estado; ou a participação, pelo contrário, dituiria os conflitos de classe, levando a população a aceitar um "compromisso" para manter inalterada a estrutura de dominação (p. 18).

A primeira hipótese é uma das inspiraçōes daquelas propostas de ação politica e administrativa que supōem possivel, e preconizam, a superaçấo dos conflitos e da dominação injusta por meio da participaçāo comunitária.

Para uma dessas utopias (51), comunidade é um ideal, uma realidade nova e capaz de vencer $e$ substituir "a mentalidade capitalista, ou seja, o desejo de lucró imediatista e individualista que impregna o mundo todo ao redor" (p. 42). Para esse fim propöe-se a participaçāo comunitária como uma nova prática e uma nova mentalidade a ser instituida no mundo do trabalho - o trabalho deve ter primazia sobre o capital. Referida à "questāo social", que gira em torno da "produçāo e da repartiçăo dos bens materiais", a proposta preconiza que "a propriedade, a gestāo e os lucros" devem ser atribuidos "nẫo ao capital mas ao trabalho"; este deveria ser realizado por "pequenas comunidades de trabalho", disseminadas "se possivel pelo pais inteiro", com gente "que já possua espirito comunitário bem desenvolvido"(p. 25) 
Uma outra proposta participativa dirige-se antes às funçōes de governo, e ao consumo, do que à produção (49). Embora inclua um item sobre "participação e integração dos empregados na vida da empresa", não se trata aqui de uma reorganização básica do trabalho ou do sistema produtivo, mas sim de garantir meios legais e administrativos de proteção ao empregado e à população em geral. Diferentemente da anterior, esta utopia ressalta, na participaçäo, a "alternativa comunitária" ao processo politico "centralizador, autoritário e elitista". Além de preconizar a participaçāo de diferentes subgrupos (moradores, juventude, empregados, etc.) nas decisöes de governo que lhe dizem respeito, também denuncia $o$ paternalismo e propõe a participação como solução - nos meios de comunicaçāo, nos planos habitacionais, na educação, na comunidade cient ifica e em outros setores de atuação governamental.

Além de bastante pragmática em suas sugestões para uma utilização "participativa" de instituiçōes, organizaçōes e movimento já existentes, esta utopia não deixa de explicitar valores genéricos básicos, tais como: "comunidade é a idéiaforça de uma politica humanista; em oposição às tendências desumanizadoras do individualismo burguês e das diferentes formas de estatismo, de esquerda ou de direita, cresce hoje em todos os meios a consciência de uma alternativa comunitária" (p. 20). Outros conceitos carregados de valor articulam "o ser" $e$ "o dever-ser" em afirmaçōes de alto teor ideológico. "A pessoa humana - e não o capital, o Estado ou o partido - constitui o sujeito, ofundamento e o fim da vida social. Mas o homem real não $\dot{e}$ um ser isolado (...) É dentro das comunidades reais que ele vive e se desenvolve. Nas comunidades ele atua. É através das comunidades que ele pode 'participar' da vida de toda a sociedade"(p. 20).

As utopias participativas em geral afirmam, sem hesitação, a existência e a urgência da participaçāo comunitária; só problematizam os meios de aplicá-la e os métodos de vencer as resistências ao seu desenvolvimento. Ao contrário, as criticas ideológicas e analiticas problematizam a própria natureza e conveniência da participação comunitária. Tais criticas geralmente tendem a favorecer a segunda hipótese formulada por Caserio de Almeida (p. 18), a saber, que a participaçấo diluiria os conflitos de classe, levando a população a aceitar um compromisso para manter inalterada a estrutura de dominaçāo.

Boa parte do material teórico $e$ descritivo da presente Bibliografia pode ser examinado com proveito na medida em que for referido ao debate sobre o caráter renovador ou conservador da "participação comunitária". E esse debate se articula com o tratamento da questão da interação regular ou da mútua exclusão entre participação comunitária e estrutura de dominação. A titulo de exemplificação, são a seguir apresentadas algumas questōes que refletem a perspectiva "politica" ressaltada nas presentes Anotações.

Até que ponto a atuação governamental tende a bloquear ou esvaziar os movimentos participativos? Até que ponto, ao contrário, a presença do governo chega a ser uma condição favorável (ou mesmo necessária) para o surgimento e a continuidade desses movimentos?

Na medida em que a participação comunitária ultrapassa o nivel da denúncia e da reivindicação, para chegar ao controle regular ou mesmo à gestäo de serviços públicos, aumenta ou diminui a autonomia do movimento participativo? Aumenta ou diminui a possibilidade de ele ter efeitos inovadores? Em que ponto a participação comunitária deixa de "fazer diferença" por ter passado à condiçấo de cooptada?

Em algumas análises, surge 0 problema do enfraquecimento (não esperado/dos movimentos participativos que obtêm atendimento a suas reivindicações - o que sugere, entre outras, a hipótese de que a reivindicação de ações especificas do governo em proveito da população pode reforçar, em vez de substituir, os vinculos clientelistas, e fortalecer $o$ individualismo em detrimento das açōes comunitárias.

Até que ponto a mobilização e a organização da participaçāo para a obtenção de creches, serviços de saúde, regularização de titulos de terrenos - por exemplo - podem contribuir para consolidar "práticas democráticas ao nivel das bases", com reflexos "na própria transformação do sistema"? Ou, na direção contrária, qual o papel da conjuntura politica democratizante, ao nivel da atuaçāo do Estado, no favorecimento aos movimentos participativos de base?

Em uma das publicaçōes aqui relacionadas, a questāo é formulada a nivel teórico mais geral (3). Nesse trabalho, as conclusôes aparentemente transcendem as duas hipóteses que foram apresentadas no inicio destas Anotaçōes, pois atribuem aos movimentos participativos um papel que não $\dot{e}$ apenas conservador, e também é algo mais do que inovador: "por promover uma acumulaçāo de reivindicaçōes e conquistas sucessivas, ao redor de necessidades históricas emergentes, de acesso a direitos fundamentais de cidadania (...) a experiência da 'democracia como identidade restrita' realizada pelos movimentos sociais tem influido positivamente nas transformaçōes mais amplas do sistema politico $e$ cultural"'(p. 295). E o texto continua: " (...) nem mesmo a repressão ou a cooptaçāo estatal têm logrado extinguir" tal experiência. A persistência dos movimentos sociais, "conquista já agora permanente (...) dos setores subordinados da sociedade (...) confere nova abrangência e significação ao território da politica e às fronteiras do Estado, no sentido não apenas da reforma constante das instituiçōes, mas ainda numa politizaçāo da vida cotidiana que tende a eliminar, ou pelo menos a reduzir, a distância que separa a sociedade da politica".

Haverá suficiente fundamentação teórico-empírica para tais afirmaçôes? $O$ estudo dos trabalhos da presente bibliografia pode contribuir para a resposta.

Obs.: as referências bibliográficas precedidas de asterisco estão dispon íveis no acervo da Biblioteca $\operatorname{Karl} A$. Boedecker, da EAESP/FGV. 
Referências bibliográficas

1. * Brasileiro, A. M. A cidade e a participação política: as associações de moradores. Revista de Administração Municipal, 34(183):6-7, Rio de Janeiro, abr./jun. 1987.

2. * Fischer, Tania. A gestão do município e as propostas de descentralização e participação popular. Revista de Administração Municipal, 34(183):18-35, Rio de Janeiro, abr./jun. 1987.

3. Scherer - Warren, Ilse \& Krischke, Paulo J. Uma revolução no cotidiano? Os novos movimentos sociais na América do Sul. São Paulo, 1987.297 p

4. Canjani, Ayrton dos Santos. Plano de ação integrada entre empresa, comunidade e poder público, para áreas sujeitas a inundações. Engenharia: a revista do Instituto de Engenharia, (456):28-33, 31 mar. - 5 maio 1986

5. * Centro Pastoral Vergueiro/Grande Imprensa. Casa própria/Movimentos populares. Folha, Estado, Diário Grande ABC, Jornal da Tarde. São Paulo, 1984/86.

6. Do esforço da população organizada nasce a vila comunitária. Participação na Grande São Paulo, 2(18), 15 - 30 out. 1986.

7. * Instituto de Pesquisas Tecnológicas. Experiência de auto-ajuda e ajuda mútua Rio de Janeiro, BNH/DEPEA, 1986. Relatório de pesquisa.

8. Jacobi, Pedro Roberto. Ação coletiva na GSP: do populismo aos dias de hoje recuperando as lutas populares urbanas por uma cidadania plena. Rio de Janeiro, FGV, 1986. 135p. (Relatório de pesquisa, 38).

9. * Moura, Erido. Na defesa do bairro, a luta pela participação. $A$ Construção em São Paulo, 39(2008):1-3, 4 ago. 1986.

$10^{*}$ Oliveira, Sérgio Murilo Ferreira de. Administração participativa: bases para a definiçâo. Revista de Administração $\mathrm{Mu}$ nicipal, 33(181):42-58, out./dez. 1986.

11. * Pequena história da associação dos favelados de Piracicaba, tal como contada por Francisco Romero, Luisinho, Dos Anjos e Elizeu. Cadernos do CEAS, (104) 26-35, jul./ago. 1986.

12. Secretaria dos Negócios Metropolita nos - Emplasa. Participação popular em transporte metropolitano. Experiências de participação popular. São Paulo, 1986 $211 \mathrm{p}$.

13. * Brasileiro, Ana Maria \& Ungaretti Maria América. As escolas comunitárias uma experiência alternativa. Revista de Administração Municipal, 32(177):62-79, out./dez. 1985.

14. * Empresa Metropolitana de Planejamento da Grande São Paulo, S.A./Secreta- ria de Estado dos Negócios Metropolitanos - Governo do Estado de São Paulo. Guia de apoio das sociedades amigos de bairros. São Paulo, 1985. 128p. (Documentos do SPAM)

15. * Instituto de Pesquisas Tecnológicas/ Divisão de edificaçōes. Manual de orienta ção para construçấo por ajuda mútua. São Paulo, 1985. 68p

16. * Massolo, Alejandra. As mulheres nos movimentos urbanos do México. Espaço \& Debates: revista de estudos regionais e urbanos, 5(14):77-92, 1985.

17. * Oliveira, Carlos. Associações de mo radores: uma luta pela desprivatização de Estado. Revista de Administraçäo Municipal, 32(176):30-9, jul./set. 1985 .

18. Participação: frente de mutirðes nos bairros. Participação na Grande São Paulo. $1(7): 8$, out./nov. 1985 .

19. * Rodriguez Lopes, Carlos; Castro, Carmem Lucia L. Veloso de \& Bortolet to, Maria Elide. A relação estado e trabalhadores urbanos no Brasil. Revista de Administração Pública, 19(3):17.48, jul./set. 1985.

20. Secretaria dos Negócios Metropolitanos - Emplasa. Programa de comunicação $e$ açāo comunitária. 01 - Edificaçōes Guia de apoio das sociedades amigos de bairros. São Paulo, maio 1985. 128p. (Documentos do SPAM).

21. * Administração municipal e participação popular. A experiência da equipe de governo Luiz Moulin, Guaçuí, 1984. 24p.

22. Brandão, Carlos Rodrigues, org. Repensando a pesquisa participante. São Paulo, 1984, 252p

23. * Caccia-Bava, Sílvio. Os conselhos e a participação dos trabalhadores. Lua Nova, 1(2):97-9, São Paulo, jul./set. 1984

24. * Cammarano, Maria Regina. Fiscalização auxiliar de transporte: uma experiência de participação. Revista do SPAM, 3 (13):32-7, dez. 1984

25. Cohab (São Paulo-município). $A$ participação da comunidade na produção de habitaçōes: Vila Cachoeirinha-SP. São Paulo, fev. 1984. 166p.

26. Comunidade participativa: a participação da comunidade na fiscalização dos ônibus e mananciais da GSP e a idéia do projeto Sistema Auxiliar de Fiscalizaçâo criado pela SNM e implantado pela Emplasa. Veja como funciona e o que representa. Participação na Grande São Paulo, 1(1): $3-4$, set. 1984

27. * Empresa Metropolitana de Planejamento da Grande São Paulo, S.A./Secretaria de Estado dos Negócios Metropolitanos - Governo do Estado de São Paulo. II Seminário paulista das sociedades amigos de bairros: Anais. São Paulo, 1984. 167p. (Documentos do SPAM).
28. * Ferrari, Levi B. Conselhos populares na cidade de São Paulo. Lua Nova, l(2): $94-6$, jul./set. 1984

29. * Hutcheson, John D. Citizen representation in neighboorhood planning. Journal of the American Planning Association, 50(2):183-93, Illinois, 1984.

30. Jacobi, Pedro Roberto. Saneamento básico e reivindicaçōes sociais na GSP: 1973/79. FGV, 1984. 99p. (Relatório de pesquisa, 30).

31. * Kaupatez, Ros Mari \& Reinach, Henrique de Castro. Projeto Vila Nova Cachoeirinha: a participação da população na produção de moradia. $A$ construção em São Paulo, 37(1885):13-6, 26 mar. 1984.

32. * Martins, Carlos Estevam. Participação nas empresas do Estado. Lua Nova, l(2) $91-3$, jul./set. 1984 .

33. * Mello, Diogo Lordello de. Associação de municípios: experiência na América Latina. Revista de Administraçẫo Municipal, 3I(172):56-63, jul./set. 1984.

34. * Organizacion panamericana de la salud. Participacion de la comunidad en la salud y el desarrollo en las americas. Washington, 1984. 91p. Publicacion cientifica $n .473$.

35. * Rocha, Nilton Almeida. Prefeituras e participação comunitária : experiência do IBAM. Revista de Administraçdo Municipal, 31 (171):26-39, abr./jun. 1984.

36. * Vieira, R. A. Amaral. Participação comunitária e democracia. Ciência e Cultura, 36(5):733-6, maio 1984 .

37. * Boschi, Renato Raul. Movimentos coletivos no Brasil urbano. Rio de Janeiro, $1983,179 p$

38. Encontro de trabalho sobre descentralização dos serviços municipais, Rio de Janeiro, 2 a 4 maio 1983. Relatório final, Rio de Janeiro, IBAM, 1983.

39. Glass, James J. A participação dos cidadãos no planejamento: a relação entre objetivos e técnicas. s.l.p., s.c.p. 1983. $25 p$.

40. Illeris, Sven. Public participation in Denmark: experience with the county "regional plans". The Town Planning Review, 54(4):425-36, Liverpool, Oct. 1983.

41. * Jacobi, Pedro Roberto. Prefeituras democráticas, movimentos populares e poder local: participação cooptação ou autonomia? Espaço e Debates: revista de estudos regionais e urbanos, 3(9):66-9, maio/ ago. 1983 .

42. * Kowarick, Lúcio. Lutas urbanas e movimentos populares: alguns pontos para reflexão. Espaço e Debates: revista de estudos regionais e urbanos, 3(8):55-63, jan./abr. 1983. 
43. * Lustosa, Waldemiro Teixeira. A ação governamental e o comportamento do consumidor. Revista de Administraçäo, 18 (2):59-69, abr./jun. 1983.

44. Richet, Vincent. Vive le referendum communal. Futuribles, (63):61-9, Paris, feb. 1983.

45. * Daniel, Celso Augusto. Poder estatal municipal: um quadro teórico e uma análise dos governos locais com participação popular no Brasil recente. São Paulo, s.c.p., 1982. 228p. Tese de mestrado.

46. Fundação João Pinheiro (Belo Horizonte). Diretoria de Planejamento Social e Urbano. A valiafāo da politica e programa de desenvolvimento comunitário: resumo informativo. Rio de Janeiro, BNH/ DEPEA, ago. 1982. 56p.

47. * Malzyner, Carlos. Movimentos sociais urbanos: um estudo de caso da zona sul de São Paulo. São Paulo, s.c.p., 1982, $136 \mathrm{p}$.

48. Moises, José Älvaro. Cidade, povo $e$ poder. Rio de Janeiro, Paz e Terra, 1982. 198p. (Coleção CEDEC/Paz e Terra, 5).

49. Montoro, Franco. Alternativa comunitária: um caminho para o Brasil. Rio de Janeiro, 1982.159p.

50. * Motta, Fernando C. Prestes. Participação e cogestão: novas formas de administração. São Paulo, Brasiliense, 1982. 81p.

51. * Santos, J. B. P. dos. Uma saida para o desemprego: comunidade de trabalho na cidade ou no campo. Petrópolis, 1982. 90p.

52. Secretaria dos Negócios Metropolitanos. Programa de comunicaçáo e ação comunitária. 01 - Ediçôes especiais - Região Metropolitana. BAC - Boletim de Ação Comunitária 1981/82: n. 11/20. São Paulo, 1982.

53. ---. Programa de comunicacato e ação comunitária. 01 - Informações. Contribuição à história dos movimentos sociais na GSP: $1968 / 1975$. São Paulo, jan. 1982. 256p.

54. Trapero, Juan-Jesus. La participacion de los ciudadanos en el planeamiento, la construccion y la gestion de los asentamientos humanos. Ciudad y Territorio: revista de ciencia urbana, (53):73-87, Madrid, jul./set. 1982.

55. * Alves, Márcio Moreira. A força do povo: democracia participativa em Lages. 3. ed. São Paulo, 1981, 150p.

56. * Cardia, Nancy das Graças. Planejadores e participacão da populaçáo do planejamento habitacional: percepçio, atitu- des e relação de poder. São Paulo, USP/ Instituto de Psicologia, 1981.

57. * Ducsik, Dennis W. Citizen participation in power plant siting: Aladdin's lamp or Pandora's box. Journal of the American Planning Association, 47(2):154-66, Apr. 1981.

58. * Ferreira, Francisco Whitaker. Planejamento sim e não. 2. ed. Rio de Janeiro, Paz e Terra, 1981. 157p.

59. Kent, George. Community -based development planning. Third World Planning Review, 3(3):313-26, Liverpool, Aug. 1981.

60. * Povo e poder público buscam modelo alternativo de desenvolvimento. $A$ Construfão em São Paulo, 34(1765):4-9, 07 dez. 1981.

61. Secretaria de Planejamento e Administração Metropolitana/Secretaria dos Negócios Metropolitanos - Emplasa. Programo de comunicação e acáo comunituria. 01 Ediçðes especiais - Política. Comunidade em debate: III Seminário A Comunidade Pergunta. São Paulo, 1981. 96p.

62. * Castells, Manuel. Cidade, democracia e socialismo. Rio de Janeiro, Paz e Terra, 1980. 193p.

63. Cebrap (São Paulo). Sđ̃o Paulo: o povo em movimento. Petrópolis, Vozes, 1980. 230p.

64. * Covre, Amaro. A comunidade no poder: Experiências do município da Boa Esperança - ES. Colatina, 1977/1980. 32p.

65. Grupo de Assessoria e Participação/ Govemador. Democracia participativa: uma certa idéia - pelo Grupo de Assessoria e Participação do Governador. São Paulo, GAP, 1980.

66. * Gonzales, Suely F. Neto. $O$ problema habitacional e a ação popular. São Paulo, Ceru/Capes, 1980, v. 13. p. 30.

67. * Serio, Amarilis Simōes Serra. et alli. A participaçáo da comunidade do processo de decisä́o em assuntos relativos a trans. portes. Fundap, São Paulo, 1980. p. 106.

68. * Silva, Luis Antonio Machado da \& Ziccardi, Alícia. Notas para uma discussão sobre "movimentos sociais urbanos". Cadernos Ceru, (13):79-95, set. 1980.

69. * Almeida, Fernando Casario de. Participação e planejamento. São Paulo, $1979.48 \mathrm{p}$

70. Rattner, Henrique, org. Brasil 1990. caminhos alternativos de desenvolvimento. São Paulo, 1979. 233p.
71. Seb (Sã่ง Paulo) Coordenadoria de Planejamento e Avaliação. Organizaçáo e participaḉo da populacão de baixa renda na regiáo metropolitana de São Paulo. São Paulo, fev. 1979. 286p. (Estudos e pesquisas, 31 ).

72. Seminário sobre planos comunitários de melhoramentos urbanos, 1 ! São Paulo, 1 a 3 dut. 1979. Anais, São Paulo, Abemurb, 1979. 90p.

73. * Secretaria dos Negócios Metropolitanos - Emplasa. Programa de comunicação e ação comunitaria. 01 - Edições especiais: habitação. Comunidade em debate: habitação popular e auto-construção. São Paulo, 1979. 35p.

74. ----. Programa de comunicação e ação comunitúria. 01 - Edições especiais - Migração. Comunidade em debate: o migrante. São Paulo, 1979. 36p.

75. * Cornely, Seno A. Planejamento e participacão comunitdria. 2. ed. São Paulo, Cortez \& Moraes, 1978. 144p.

76. Sanchez del Rio, Roger. Lugar de la informacion en el planejamento: sistemas de inteligencia y participacion cidadanas. Ciudad y territorio: revista de ciencia politica, (4) $51-60$, Madrid, out./ dez. 1978.

77.--_-. Planejamiento y participacion ciudadana en los Estados Unidos. Ciudad " territorio: revista de ciencia urbana, (4): 9-24, Madrid, oct./dic. 1977.

78. * Secretaria de Estado dos Negócios Metropolitanos - Emplasa. Participaçāo comunitória. S5o Paulo, 1977. 169p. (Documentos, 2).

79. Sistema de Planejamento e Administração Metropolitana/Secretaria dos Negócios Metropolitanos - Emplasa. 01 - Edições especiais - Política. Participaçđ̃o comunitdria. São Paulo, 1977. 169p. (Documentos, 2).

80. * Camargo, Candido Procópio Ferreira de. São Paulo 1975: crescimento e pobreza. São Paulo, 1976, 155p.

81. * Singer, Paul. Economia politica da urbanização. São Paulo, 1975. 152p.

82. * Organizacion Panamericana de la Salud. Utilizacion de auxiliares y lideres comunitarios en programas de salud en el area rumal: informe final. Washington, 1974. 23p. (Publicacion cientifica, 296).

83. * Sebes/Depto. de Habitação e Trabalho. Estudos sobre mutirão. São Paulo, 1971.

84. * Avezuela, M. Formacion de dirigentes $y$ organizacion de grupos comunitarios. Barcelona, 1968. 154p. 